\title{
Effect of naloxone hydrochloride on $\beta$-EP, CD4+, CD8+, IL- 2 , MMP-9 and S100-B levels in peripheral blood after traumatic brain injury in rats
}

\author{
Feng $\mathrm{Du}^{*}$, Dedong Zhang \\ Emergency Department, The Second People's Hospital of Lanzhou City, No. 1 West Street and Zhengxi Street, Railway, \\ Chengguan District, Lanzhou City 730000, Gansu Province, China
}

*For correspondence: Email: x2716x@163.com

\begin{abstract}
Purpose: To study the influence of naloxone hydrochloride on traumatic brain injury (TBI).

Methods: Three groups of rats were used: normal control, TBI, and TBI + naloxone hydrochloride groups (12 rats/group). In the control group, only the osseous foramen was opened. Rats in TBI group were intraperitoneally injected with normal saline, while the naloxone group received naloxone hydrochloride injection at the same time. Changes in peripheral blood $\beta-E P, C D 4+, C D 8+, I L-2$, and S100-B levels; and brain tissue MMP-9 were assessed.

Results: The levels of $\beta-E P$ in the TBI- and naloxone-treated rats were higher than control values, while levels of $C D 4+$ in TBI and naloxone groups were significantly lower than those of control group ( $p<$ 0.01). At every time point, $C D 8+$ level in naloxone group was significantly lower than that in TBI group ( $p$ $<0.01$ ). Compared with control group, the levels of IL-2 in the TBI and naloxone groups were significantly lower. Higher levels of S100-B were seen in TBI- and naloxone-treated rats, relative to control value. In the naloxone group, MMP-9 expression was downregulated, when compared to the expression TBI rats $(p<0.05)$.

Conclusion: Naloxone hydrochloride reduces $\beta-E P$, alleviates inflammation, protects nerve cells and reduces brain injury in TBI rats. There is, thus, a potential to develop naloxone for the management of brain injury
\end{abstract}

Keywords: Naloxone hydrochloride, Traumatic brain injury, $\beta$-endorphin, CD4+, CD8+, IL-2, MMP-9, CNS-specific protein

\begin{abstract}
This is an Open Access article that uses a fund-ing model which does not charge readers or their institutions for access and distributed under the terms of the Creative Commons Attribution License (http://creativecommons.org/licenses/by/4.0) and the Budapest Open Access Initiative (http://www.budapestopenaccessinitiative.org/read), which permit unrestricted use, distribution, and reproduction in any medium, provided the original work is properly credited.
\end{abstract}

Tropical Journal of Pharmaceutical Research is indexed by Science Citation Index (SciSearch), Scopus, International Pharmaceutical Abstract, Chemical Abstracts, Embase, Index Copernicus, EBSCO, African Index Medicus, JournalSeek, Journal Citation Reports/Science Edition, Directory of Open Access Journals (DOAJ), African Journal Online, Bioline International, Open-J-Gate and Pharmacy Abstracts

\section{INTRODUCTION}

Traumatic brain injury (TBI) refers to organic brain injury caused by violence on the head. Cerebral ischemia and hypoxia, inflammatory reactions and many other pathological changes occur in TBI. The rate of TBI-associated mortality and disability is high. Indeed, TBI is one of the most frequently seen acute/critical diseases in brain surgery [1]. With developments in social sciences and technology, the mortality rate associated with $\mathrm{TBI}$ has decreased, but secondary infection after trauma is still a major cause of disability and death. It has been 
reported that $\mathrm{TBI}$ disrupts balance in immune function and inhibits cellular immune function mediated by $T$ lymphocytes [2]. Interleukin-2 (IL2 ) is produced in activated $T$ cells, and it participates in immune responses and anti-virus infection.

The CNS-specific protein (S100-B) is a calciumbinding protein present in the glial cells of the central nervous system and the peripheral nervous system. When brain tissue is damaged, $\mathrm{S} 100-\mathrm{B}$ is secreted in large quantities and rapidly released into the blood [3]. Matrix metalloproteinase-9 (MMP-9) belongs to the family of matrix metalloproteinases. It is secreted from intracellular to extracellular compartment in the form of a proenzyme. The occurrence and development of cerebral edema are closely related to the level of MMP-9. The permeability of blood-brain barrier (BBB) increases with increases in the level of MMP-9, thereby exacerbating the occurrence of cerebral edema [4]. It has been reported that the levels of IL-2, S100-B, MMP-9 and other factors are associated with the prognosis of TBI patients. $\beta$-Endorphin $(\beta-E P)$ is an endogenous morphine-like hormone which acts as a natural analgesic [5]. Naloxone hydrochloride is an opioid receptor antagonist which completely or partially reverses respiratory inhibition induced by opioid drugs, and it also exerts protective effect on brain tissue [6]. This study was carried out to determine the influence of naloxone hydrochloride on $\beta-E P, C D 4+, C D 8+$, IL-2, MMP-9 and S100-B expressions in peripheral blood of rats after TBI.

\section{EXPERIMENTAL}

\section{Experimental animals}

Thirty-six healthy, clean-grade Wistar rats (mean weight $=230 \pm 20 \mathrm{~g}$ ) were supplied by Shanghai Ruitaimosi Biotechnology Co., Ltd [production license = SCXK (Shanghai) 2016-0001]. This research was approved by the Animal Ethical Committee of The Second People's Hospital of Lanzhou City, Lanzhou City, China (approval no. 201713462), and was performed according to the guidelines revised "Principles of Laboratory Animal Care" (NIH publication no. 85-23) [7].

\section{Instruments and reagents}

Low temperature high speed centrifuge (model 3$18 \mathrm{~K}$ ) was product of SIGMA (Germany); Low speed centrifuge (model DT5-1B) was obtained from Changsha Xiangrui Centrifuge Co. Ltd.; Flow cytometry was purchased from Cell Signaling Technology (CST) Corporation, USA, while refrigerator (model BCD-470WDPG) was product of Qingdao Haier Group. Mouse anti-rat IgG1-PE antibody was produced by Beijing Xinbosheng Biotechnology Co., Ltd; FITC labeled mouse anti-rat $\mathrm{CD} 4+$, and CD8+ antibody were obtained from Shanghai Xianyi Chemical Technology Co., Ltd; $\beta$-EP kit was product of Shanghai Mianji Biotechnology Co., Ltd.; ELISA kits were produced by Shanghai Thermo Fisher Technology Co., Ltd, while naloxone hydrochloride was supplied by Chengdu Yuan Dong Pharmaceutical Co., Ltd. (domestic) (SFDA approval no. H20173316, specification, $2 \mathrm{ml}: 2 \mathrm{mg}$ ).

\section{Establishment and grouping of rat groups}

The rats were fasted for $8 \mathrm{~h}$ before operation. All rats were exposed to the top bone after anesthesia. A small hole was drilled through the skull, and the dura mater remained intact during the process. After hitting the rats with a heavy object in a free fall, resulting in a brief cessation of breathing, the wound was hemostatic. Then, the bone hole was closed with bone wax, and the scalp was sutured. The rats were fed in separate cages after recovery. Using the random digital method, 36 rats were assigned to sham-operated (control), and $\mathrm{TBI}+$ naloxone (naloxone) groups (12 rats/group). In the control group, only the osseous foramen was opened to expose the dura mater without injury. The TBI group was intraperitoneally injected with normal saline, while the naloxone group received naloxone hydrochloride injection at the same time point. The treatments lasted for $24 \mathrm{~h}$, after which the rats were sacrificed.

\section{Treatment indices}

Arterial blood $(5 \mathrm{~mL})$ was taken from each rat, and the plasma was obtained after centrifugation. Rats in each group were tested at 6, 12 and $24 \mathrm{~h}$ for the levels of CD4+ and CD8+ of T-lymphocyte sub-populations using flow cytometry. The plasma levels of IL-2 and S100-B were determined using enzyme-linked immunosorbent assay (ELISA) kits as per manufacturer's protocol, while $\beta$-EP level was assayed with radioimmunoassay. The expression of MMP-9 in brain tissue of rats after TBI was determined with chemiluminescence, while hematoxylin and eosin ( $H$ \& $E$ ) staining was used to observe changes in brain tissue of rats at different time points after injury.

\section{Statistical analysis}

The results are presented as mean \pm standard deviation (SD). Measurement data were statistically compared using independent sample 
$t$-test; counting data were compared with $\mathrm{x}^{2}$ test, while ranked data were compared with the Ridit test. All statistical analyses were carried out with SPSS20.0 software package. Statistical significance was fixed at $p<0.05$.

\section{RESULTS}

\section{$\beta$-EP levels in rats}

As shown in Table 1, $\beta$-EP levels in the TBI and naloxone groups were significantly higher than control values $(p<0.01)$. In the TBI and naloxone groups, $\beta$-EP attained maximum values at $6 \mathrm{~h}$, decreased gradually at the $12^{\text {th }} \mathrm{h}$ and $24^{\text {th }}$ $h$, but was lower in naloxone-treated rats than that in TBI-exposed rats $(p<0.01)$.

Table 1: $\beta$-EP levels in rats (mean $\pm S D, n=12$ )

\begin{tabular}{lccc}
\hline \multirow{2}{*}{ Group } & \multicolumn{3}{c}{$\boldsymbol{\beta}$-EP $(\mathbf{p g} / \mathbf{m l})$} \\
\cline { 2 - 4 } & $\mathbf{6} \boldsymbol{h}$ & $\mathbf{1 2} \boldsymbol{h}$ & $\mathbf{2 4} \boldsymbol{h}$ \\
\hline \multirow{2}{*}{ Control } & $118.48 \pm$ & - & - \\
& 11.88 & - & $156.35 \pm$ \\
TBI & $213.96 \pm$ & $178.98 \pm$ & 9.45 \\
& 26.31 & 4.22 & $114.38 \pm$ \\
Naloxone & $198.92 \pm$ & $131.65 \pm$ & 11.91 \\
$F$ & 18.96 & 11.49 & 9.582 \\
$p$ & 79.54 & 13.395 & $<0.001$ \\
\hline
\end{tabular}

\section{CD4+ and CD8+ in T-lymphocytes}

As shown in Table 2, there were lower levels of $\mathrm{CD} 4+$ in the TBI- and naloxone-treated rats than in control rats. The CD4+ level in TBI-treated rats was lowest at $12 \mathrm{~h}$, and then increased gradually, but was still smaller, when compared with control value at $24 \mathrm{~h}$. In the naloxone group, CD4+ level was significantly higher than that in TBI group at all time points $(p<0.01)$. In both groups, higher CD8+ values were obtained, relative to control value. The level of CD8+ in TBI group peaked at $12 \mathrm{~h}$, and then decreased gradually, but it was higher than the corresponding control group value at $24 \mathrm{~h}$. The CD8+ level in naloxonetreated rats was significantly lower than that in TBI group at each period $(p<0.01)$.

\section{IL-2 and S100-B levels}

Table 3 shows the levels of IL-2 and S100-B in the three groups of rats. Relative to control, IL-2 in the TBI and naloxone groups were lower. In both groups (naloxone and TBI), IL-2 peaked at 6 $\mathrm{h}$, and then slowly became reduced, at $12 \mathrm{~h}$ and $24 \mathrm{~h}$, although it was higher in the naloxonetreated rats than in TBI-treated rats at all time points $(p<0.01)$. In contrast, S100-B levels in $\mathrm{TBI}$ and naloxone groups were superior to corresponding control value. The level of S100-B in TBI group peaked at $24 \mathrm{~h}$, but decreased in naloxone-treated rats, relative to TBI-treated rats at each time point $(p<0.01)$.

\section{MMP-9 expression in brain tissue}

As shown in Table 4, relative to control, MMP-9 expressions in TBI and naloxone groups were upregulated $(p<0.01)$. The expression of MMP9 in TBI group started increasing at $6 \mathrm{~h}$, peaked at $12 \mathrm{~h}$, and then decreased gradually, although it was higher than control value $(p<0.05)$. The expression of MMP-9 in the naloxone group was significantly lower than that in TBI group $(p<$ 0.05).

Table 2: CD4+ and CD8+ in T-lymphocyte level (mean \pm SD, $n=12$ )

\begin{tabular}{|c|c|c|c|c|c|c|}
\hline \multirow{2}{*}{ Group } & \multicolumn{3}{|c|}{ CD4+ (\%) } & \multicolumn{3}{|c|}{ CD8+ (\%) } \\
\hline & $6 h$ & $12 \mathrm{~h}$ & $24 h$ & $6 \mathrm{~h}$ & $12 h$ & $24 h$ \\
\hline Control & $64.49 \pm 2.28$ & - & - & $\begin{array}{c}21.93 \pm \\
1.78\end{array}$ & - & - \\
\hline TBI & $55.64 \pm 1.25$ & $51.02 \pm 8.17$ & $\begin{array}{c}53.73 \pm \\
4.28\end{array}$ & $\begin{array}{c}25.11 \pm \\
1.91\end{array}$ & $\begin{array}{c}28.89 \pm \\
1.84\end{array}$ & $\begin{array}{c}26.16 \pm \\
1.58\end{array}$ \\
\hline Naloxone & $59.18 \pm 2.31$ & $61.88 \pm 5.77$ & $\begin{array}{c}62.24 \pm \\
2.72\end{array}$ & $\begin{array}{c}23.56 \pm \\
1.82\end{array}$ & $\begin{array}{c}21.96 \pm \\
1.19\end{array}$ & $\begin{array}{c}21.06 \pm \\
1.19\end{array}$ \\
\hline$F$ & 60.46 & 3.761 & 5.813 & 8.99 & 10.955 & 8.932 \\
\hline$P$ & $<0.001$ & 0.001 & $<0.001$ & $<0.001$ & $<0.001$ & $<0.001$ \\
\hline
\end{tabular}

Table 3: IL-2 and S100-B levels in rats (mean \pm SD, $n=12$ )

\begin{tabular}{lcccccc}
\hline \multirow{2}{*}{ Group } & \multicolumn{9}{c}{$\mathbf{I L - 2}$} & \multicolumn{3}{c}{$\mathbf{S 1 0 0 - B}$} \\
\cline { 2 - 7 } & $\mathbf{6} \boldsymbol{h}$ & $\mathbf{1 2} \boldsymbol{h}$ & $\mathbf{2 4} \boldsymbol{h} \boldsymbol{h}$ & $\mathbf{1 2} \boldsymbol{h}$ & $\mathbf{2 4} \boldsymbol{h}$ \\
\hline Control & $70.58 \pm 7.04$ & - & - & $0.74 \pm 0.31$ & - & - \\
TBI & $61.03 \pm 4.98$ & $59.04 \pm 3.18$ & $55.98 \pm 3.44$ & $1.22 \pm 0.15$ & $1.38 \pm 0.18$ & $1.48 \pm 0.19$ \\
Naloxone & $67.94 \pm 4.36$ & $65.85 \pm 3.37$ & $64.52 \pm 2.98$ & $0.92 \pm 0.27$ & $0.79 \pm 0.37$ & $0.76 \pm 0.29$ \\
$F$ & 9.38 & 5.091 & 6.501 & 11.05 & 4.967 & 7.307 \\
$P$ & $<0.001$ & 0.001 & $<0.001$ & $<0.001$ & $<0.001$ & $<0.001$ \\
\hline
\end{tabular}


Table 4: MMP-9 expression in brain tissue of rats (mean $\pm \mathrm{SD}, \mathrm{n}=12$ )

\begin{tabular}{lccc}
\hline \multirow{2}{*}{ Group } & \multicolumn{3}{c}{ MMP-9 } \\
\cline { 2 - 4 } & $\mathbf{6} \boldsymbol{h}$ & $\mathbf{1 2} \boldsymbol{h}$ & $\mathbf{2 4} \boldsymbol{h}$ \\
\hline \multirow{2}{*}{ Control } & $36.82 \pm$ & - & - \\
& 2.06 & $71.62 \pm$ & $58.76 \pm$ \\
TBI & $52.65 \pm$ & 10.79 & 8.86 \\
& 5.55 & $40.29 \pm$ & $39.06 \pm$ \\
Naloxone & $44.26 \pm$ & 7.63 & 5.32 \\
$F$ & 6.25 & 8.213 & 6.603 \\
$P$ & 30.47 & $<0.001$ & $<0.001$ \\
\hline
\end{tabular}

\section{Morphological features of brain injury in rats}

In the control group, the intercellular arrangement of brain tissue was orderly; the structure was normal, and the intercellular substance was compact. No swelling of brain cells or atrophy of glial cells was observed (Figure $1 \mathrm{~A}$ ). In the TBI group, the intercellular arrangement was disordered, the intercellular substance was loose, the cell structure was abnormal, and glial cell swelling and thrombosis were seen (Figures 1 B - D). In the naloxone group, the intercellular arrangement tended to be neat, and no thrombus formation was seen (Figures $1 \mathrm{E}-\mathrm{G}$ ).

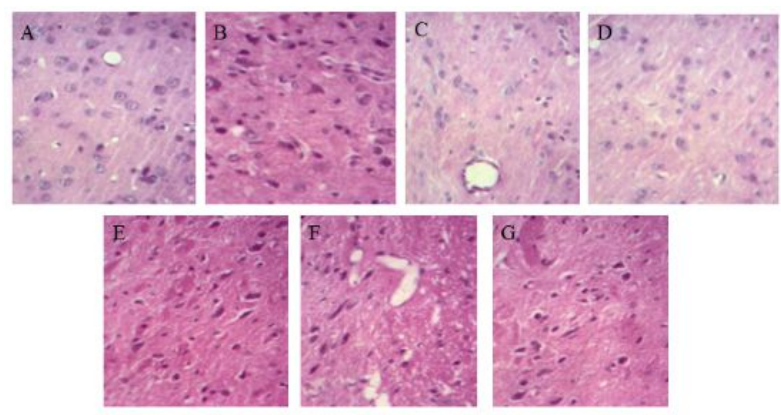

Figure 1: Brain sections of rats from the three groups. A: Control group showing normal features; B - D: Changes in brain tissue in TBI group at $6 \mathrm{~h}, 12 \mathrm{~h}$ and $24 \mathrm{~h}$; $\mathrm{E}$ - G: Changes in brain tissue in naloxone group at $6 \mathrm{~h}, 12 \mathrm{~h}$ and $24 \mathrm{~h}(\mathrm{H} \& \mathrm{E}, \times 400)$

\section{DISCUSSION}

Traumatic brain injury (TBI) refers to the serious consequences of trauma to the brain tissue, such as neurological dysfunction, nerve cell death and glial cell death. It has adverse effects on the quality of life, and it is associated with high incidence of total body trauma, disability and death [8]. At present, the efficacy of naloxone hydrochloride is widely accepted, and it has become one of the most important drugs in the treatment of TBI. The present study was carried out to determine the influence of naloxone on $\beta$ EP, CD4+, CD8+, IL-2, MMP-9 and S100-B levels in peripheral blood of rats after TBI, in order to make available a more accurate scientific basis for its use in the treatment of TBI.

Naloxone hydrochloride is an opioid receptor $\mu$, $\mathrm{K}, \quad \alpha$ specific blocker which competitively combines with the central nervous system and the peripheral $\mu, \zeta$, $\mathrm{k}$ receptors, thereby inhibiting the generation of endogenous toxic products such as oxygen free radicals and nitric oxide (NO) after TBI [9]. $\beta$-Endorphin $(\beta-E P)$ is an endogenous opioid peptide with morphine-like effects secreted by the pituitary and hypothalamus. When the body experiences pain, it releases the endogenous opioid to fight the pain, and the function of the immune system is enhanced under the excitation of $\beta$-EP [10].

Some studies have shown that after TBI, the content of $\beta$-EP increases significantly, the function of the central nervous system is inhibited, while the patients experience different degrees of consciousness disorders [11]. It has been reported that naloxone hydrochloride antagonizes the effect on $\mathrm{K}$ and $\alpha$ receptors, protects nerve cells, and promotes the recovery of nervous system function [12]. In this study, $\beta$ EP levels in the TBI and the naloxone groups were significantly increased, relative to control values, and $\beta$-EP level in the naloxone group was significantly lower than that in the TBI group, following naloxone hydrochloride treatment. These results indicate that naloxone hydrochloride can significantly reduce $\beta$-EP levels and promote the recovery of brain tissue and nerve function.

It is believed that the nature of secondary brain injury after TBI manifests as a series of immunosuppression and inflammatory responses which further compromise neuroendocrineimmuno-regulatory functions, resulting in destruction of the structure of the nerve cell. Some scholars have established an important relationship between secondary infection after $\mathrm{TBI}$ and abnormal immune function [13]. Neuroendocrine immunity, which is centered on hypothalamus-pituitary-adrenal gland axis, regulates the immune system through hormonal action, neurotransmitters, endogenous opioid peptide and sympathetic nerves.

The important effector cells of cellular immunity are auxiliary $\mathrm{T}$ lymphocytes (Th, CD4+) and suppressive $\mathrm{T}$ lymphocytes (Ts, CD8+). The CD4+ is activated by macrophages, and it triggers inflammation, while CD8+ damages target cells that express antigens by secreting cytotoxins. Interleukin-2 (IL-2) is a cytokine synthesized by $\mathrm{T}$ lymphocytes (especially CD4+ 
$\mathrm{T}$ cells) when stimulated by antigens or tear elements. It exists in the central nervous system and peripheral blood, and it participates in a series of pathological and physiological processes while playing an immune-regulatory role. It has been reported that after $\mathrm{TBI}$, the content of $\beta$-EP in the peripheral blood is appreciably increased, resulting in inhibition of the expression of CD4+ so that the secretion of IL-2 is reduced; CD8+ is increased, the immune function of the cell is inhibited, and the immune balance is destroyed [14].

In the present study, the levels of CD4+ and IL-2 in the TBI and naloxone groups were decreased, when compared with control values, and the levels of IL-2 and CD4+ in the naloxone-treated rats were higher than corresponding values in the TBI-treated rats. The CD8+ levels in the TBI and naloxone groups were significantly higher than control value, and the CD8+ level in the naloxone-treated rats was significantly lower than that in the TBI-treated rats at each time point. These findings indicate that TBI impairs immune balance, inhibits cellular immune function and triggers inflammatory reactions. The results also suggest that naloxone hydrochloride inhibits the high expression of CD8+ after TBI, and reduces the TBI-associated inflammatory reactions.

Following TBI, local cerebral tissue ischemia and hypoxia result, leading to the destruction of blood brain barrier (BBB). The BBB is mainly composed of capillary endothelial cells, vascular basement membrane and glial cells, which jointly maintain the stability of the internal environment of the nervous system. The destruction of BBB results in increased permeability of blood vessels and aggravates brain edema [15].

Matrix metalloproteinase-9 (MMP-9) belongs to the MMP family and its main function is to degrade and reconstruct extracellular matrix. It is closely linked to the destruction of BBB and the occurrence and development of brain edema after TBI. In the present study, the expressions of MMP-9 in TBI and naloxone groups were significantly higher than the corresponding control expression. Moreover, the expression of MMP-9 in the naloxone-treated rats was significantly low, relative to the TBI-treated rats. Therefore, it can be reasonably inferred that naloxone hydrochloride inhibits the expression of MMP-9 and alleviates secondary brain edema after TBI.

The $\mathrm{S} 100$ protein was first found in bovine brain by Moore et al. One of the main components of $\mathrm{S} 100$ is $\mathrm{S} 100-\mathrm{B}$ which consists of two $\beta$ chains. It is an acidic calcium-coupled protein found mainly in glial cells. Low level S100-B nourishes the nerves and positively affects nerve growth and repair after injury [16]. Previous studies found that following $\mathrm{TBI}$, glial cells secrete excessive S100-B, leading to a rapid increase in S100-B levels. In this investigation, S100-B levels were increased in TBI- and naloxone-treated rats, relative to control rats, and its level in the naloxone-treated rats was significantly lower than that in TBI group at each time point. These findings show that naloxone hydrochloride inhibits the secretion of S100-B and reduces brain damage. In addition, the results indicate that the level of $S 100-B$ protein is of great significance to the assessment of the severity of TBI.

\section{CONCLUSION}

The results obtained in this study indicate that naloxone hydrochloride reduces the level of $\beta$-EP and promotes the expression of CD4+ in TBI rats, leading to enhancement of secretion of IL-2, inhibition of expression of CD8+, alleviation of inflammatory reactions and improvement of immune function. At the same time, naloxone hydrochloride inhibits the expressions of MMP-9 and S100-B protein, protects blood brain barrier and reduces brain damage. Thus, naloxone hydrochloride can be potentially be developed to manage traumatic brain injury.

\section{DECLARATIONS}

\section{Conflict of Interest}

No conflict of interest associated with this work.

\section{Contribution of Authors}

We declare that this work was done by the author(s) named in this article and all liabilities pertaining to claims relating to the content of this article will be borne by the authors. All authors read and approved the manuscript for publication. Feng Du conceived and designed the study, Feng Du, Dedong Zhang collected and analysed the data, while Dedong Zhang wrote the manuscript.

\section{Open Access}

This is an Open Access article that uses a funding model which does not charge readers or their institutions for access and distributed under the terms of the Creative Commons Attribution License (http://creativecommons.org/licenses/by/ 4.0) and the Budapest Open Access Initiative (http://www.budapestopenaccessinitiative.org/rea 
d), which permit unrestricted use, distribution, and reproduction in any medium, provided the original work is properly credited.

\section{REFERENCES}

1. Wei XJ, Chen ZF, Fu XJ, Xu XL, Pan HS, Xie QS. Effect of naloxone hydrochloride on neuronal cell apoptosis and cerebral edema induced by experimental brain injury. Chin J Emerg Med 2016; 18(3): 281-285.

2. Povlishock JT. The classification of traumatic brain injury (TBI) for targeted therapies. J Neurotrauma 2018; 25(7): 717-718.

3. Pelinka LE, Kroepfl A, Leixnering M, Buchinger W, Raabe $A$, Redl $H$. GFAP versus $S 100 B$ in serum after traumatic brain injury: relationship to brain damage and outcome. J Neurotrauma 2014; 21(11): 1553-1561.

4. Jiang GY, Luo C, Peng X. Effects of Muscone on the Expression of MMP9 Protein after Traumatic Brain Injury in Rats. J Emerg Tradit Chin Med 2018; (1): 90-93.

5. Bian XX, Yuan XS, Qi CP. Effect of rhEPO on S100B protein and IL-6 expressions in serum of rats after traumatic brain injury. Jiangsu Med J 2016; 35(11): 1306-1308.

6. Sun $Y H$, Meng $H$, Zhang $Y Z$, Li QG, Sun MZ, Wang $H Y$, $H e$ L. The pharmaceutic effect of Nalxotone on $S D$ rats with head trauma. Chin J Neurosurgery 2014; 20(2): 167-169.

7. World Health Organization. Principles of laboratory animal care. WHO Chron 1985; 39: 51-56.

8. Yuan XS, Bian XX, Qi CP. The protective effects of Xuebijing on rats after traumatic brain injury. J Jiangsu Univ (Med Edit) 2017; 19(1): 35-38.

9. Hammond FM, Bickett AK, Norton JH, Pershad R. Effectiveness of amantadine hydrochloride in the reduction of chronic traumatic brain injury irritability and aggression. J Head Trauma Rehabil 2013; 29(5): 391 399.

10. Liang $P$, Zhai $X, W u N$, Zhou YD, Li YL, Chen ZY, Li LS, $X i a$ ZZ. Experimental investigation on effect of cell immunity after naloxone hydrochloride treated severe traumatic brain injury in rats. Laser J 2014; 31(2): 73-74.

11. Hao J, Luo JS, Weng Q, He Y, Liu J, Yang MH, Bian GY, Liu T. Effects of dexmedetomidine on sedation and $\beta$ endorphin in traumatic brain injury: a comparative study with propofol]. Zhonghua Wei Zhong Bing JiJiu Yi Xue 2013; 25(6): 373-376.

12. Jing JJ, Wang SS, Yang QW, Wang RM, Gao JX, Zhao $L$. Effect of naloxone hydrochloride on c-fos protein expression in brain and plasma beta-endorphin level in rats with diffuse brain injury and secondary brain insult. Med J Chin People's Liberation Army 2012; 37(9): 864867.

13. Hua R, Mao SS, Zhang YM, Chen FX, Zhou ZH, Liu JQ. The effects of PACAP on $C D 4+/ C D 8+T$ cells in rats with traumatic brain injury. Chin J Emerg Med 2016; 21(6): 572-576.

14. Hua R, Mao SS, Zhang YM, Chen FX, Zhou ZH, Liu JQ. Effects of pituitary adenylatecyclase activating polypeptide on $C D 4(+) / C D 8(+) \quad T$ cell levels after traumatic brain injury in a rat model. World J Emerg Med 2016; 3(4): 294-298.

15. Chodobski A, Zink BJ, Szmydynger-Chodobska J. BloodBrain Barrier Pathophysiology in Traumatic Brain Injury. Trans/ Stroke Res 2011; 2(4): 492-516.

16. Pelinka LE, Kroepfl A, Leixnering M, Buchinger W, Raabe $A$, Redl H. GFAP versus $S 100 B$ in serum after traumatic brain injury: relationship to brain damage and outcome. J Neurotrauma 2014; 21(11): 1553-1561. 